\title{
Perbandingan Analisa Perkerasan Metode Bina Marga Revisi Juni 2017 dan AASHTO 1993 (Studi Kasus pada Pekerjaan Rencana Preservasi Ruas Jalan Jatibarang-Langut TA 2017)
}

\author{
SONY SUMARSONO, HERU JUDI H GULTOM \\ Jurusan Teknik Sipil, Institut Teknologi Nasional, Bandung \\ Email: Sumarsonosony15@yahoo.com
}

\begin{abstract}
ABSTRAK
Jalan raya merupakan salah satu prasarana transportasi di Indonesia yang sering digunakan untuk menunjang kegiatan perekonomian khususnya pada jalan nasional. Namun, seringkali di jalan nasional terdapat kerusakan-kerusakan pada perkerasan jalan yang membuat kenyamanan pengendara terganggu. Salah satu ruas jalan nasional tersebut adalah jalan Jatibarang-Langut yang berada di jalur Pantura Jawa Barat. Pengujian yang dilakukan untuk mengetahui penyebab kerusakan perkerasan jalan tersebut yaitu survei traffic counting dan pengujian lendutan dengan alat Falling Weight Deflectometer (FWD) yang dalam perencanaan perhitungan tebal perkerasan akan dibandingkan menggunakan metode Bina Marga Revisi Juni 2017 dan AASHTO 1993. Data sekunder yang diperlukan adalah data daya dukung tanah dasar. Data primer yang diperoleh yaitu volume lalu lintas dan pengujian lendutan. Hasil perhitungan modulus tanah dasar 34,34 MPa dan modulus perkerasan 1.806,80 MPa. Sedangkan hasil perhitungan tebal perkerasan dengan CESA metode Bina Marga Revisi Juni 2017 47,42 cm dan CESA AASHTO $199338,74 \mathrm{~cm}$.
\end{abstract}

Kata kunci: Jatibarang-Langut, survei traffic counting, Falling Weight Deflectometer (FWD), Bina Marga Revisi Juni 2017, AASHTO 1993.

\begin{abstract}
The highway is one of the transportastion infrastructure in Indonesia which is often used to support economy activities especially on national road. However, often on the national road there are damages on pavement that makes disturbed rider's comfort. The one of the national road segment is road Jatibarang-Langut located on the path Pantura, west Java. The testing done determine the cause of the pavement damege is survey traffic counting and deflection testing with Falling Weight Deflectometer (FWD) in planning pavement thickness calculation will be compared by using Bina Marga method Revision June 2017 and AASHTO 1993. The secondary data required is ground carrying capacity data. The primary data required os traffic volume and deflection testing. The calculation results of the basic soil modulus 34,34 MPa and pavement modulus 1.806,80 MPa. While the results of pavement thickness calculation by CESA method Bina Marga Revision June 2017 47,42 cm dand CESA AASHTO 1993 38,74 cm.
\end{abstract}

Keywords: Jatibarang-Langut, survey traffic counting, Falling Weight Deflectometer (FWD), Bina Marga Revision June 2017, AASHTO 1993. 


\section{PENDAHULUAN}

Jalan raya merupakan salah satu prasarana transportasi di Indonesia yang sering digunakan untuk menunjang kegiatan perekonomian ataupun kegiatan-kegiatan manusia sehari-hari khususnya pada jalan nasional. Namun seringkali dijumpai pada jalan nasional terdapat kerusakan-kerusakan pada perkerasan jalan karena volume lalu lintas yang padat ditambah dengan kendaraan-kendaraan berat yang melewatinya. Salah satu ruas jalan nasional yang biasanya mendapatkan kerusakan-kerusakan pada perkerasan adalah ruas jalan JatibarangLangut yang berada di Jalur Pantai Utara yang menghubungkan antar provinsi di pulau Jawa. Salah satu lokasi ruas jalan Jatibarang-Langut yang terdapat kerusakan pada perkerasan adalah KM 53+000-49+900 arah Jakarta. Untuk itu, pada tahun 2017 ruas jalan JatibarangLangut Km 53+000-49+900 arah Jakarta dilakukan survei dan pengujian untuk mengetahui permasalahan pada perkerasan tersebut. Survei yang dilakukan adalah survei traffic counting dan pengujian lendutan dengan alat Falling Weight Deflectometer (FWD). Dari survei dan pengujian diharapkan permasalahan yang terjadi dapat diselesaikan sehingga dalam jenis penanganannya dapat sesuai dengan kondisi dan hasil penelitian di lapangan. Dalam hal ini metode yang digunakan dalam perencanaan tebal perkerasan adalah dengan menggunakan metode Bina Marga Revisi Juni 2017 dan metode AASHTO 1993.

\section{TINJAUAN PUSTAKA}

\subsection{Beban Lalu Lintas}

Menurut Sukirman, S. (2010) beban lalu lintas adalah beban kendaraan yang dilimpahkan ke perkerasan jalan melalui kontak antara ban dan muka jalan. Beban lalu lintas merupakan beban dinamis yang terjadi secara berulang selama masa pelayanan jalan. Besarnya beban lalu lintas dipengaruhi oleh berbagai faktor kendaraan seperti:

1. Konfigurasi sumbu dan roda kendaraan.

2. Beban sumbu dan roda kendaraan.

3. Tekanan ban.

4. Volume lalu lintas.

5. Repitisi sumbu.

6. Distribusi arus lalu lintas pada perkerasan jalan.

7. Kecepatan kendaraan.

\subsection{Analisis Volume Lalu Lintas}

Parameter yang penting dalam analisis struktur perkersan adalah data lalu lintas yang diperlukan untuk menghitung beban lalu lintas rencana yang dipikul oleh perkerasan sesama umur rencana. Beban dihitung dari volume lalu lintas pada tahun survei yang selanjutnya diproyeksikan ke depan sepanjang umur rencana. Volume tahun pertama adalah volume tahun lalu lintas sepanjang tahun pertama setelah perkerasan diperkirakan selesai dibangun atau direhabilitasi (Sumber: Direktorat Jenderal Bina Marga, 2004).

\subsection{Daya Dukung Tanah Dasar}

Menurut Sukirman, S. (2010) tanah dasar dapat terdiri dari tanah dasar tanah asli, tanah dasar tanah galian, atau tanah dasar tanah urug yang disiapkan dengan cara dipadatkan. Di atas lappisan tanah dasar diletakkan lapisan struktur perkerasan lainnya, oleh karena itu mutu daya dukung tanah dasar ikut mempengaruhi mutu jalan secara keseluruhan. 
Perbandingan Analisa Perkerasan Metode Bina Marga Revisi Juni 2017 dan AASHTO 1993 (Studi Kasus pada Pekerjaan Rencana Preservasi Ruas Jalan Jatibarang-Langut TA 2017)

\subsection{Pengujian Pengukuran Lendutan Dengan Alat Falling Weight Deflectometer (FWD)}

Pusat Litbang Jalan Departemen Pekerjaan Umum (Pusjatan) memiliki beberapa alat penyelidikan lapangan dengan alat Falling Weight Deflectomter (FWD). Dimana pengoperasiannya dan evaluasinya dilakukan secara komputerisasi. Alat FWD ini telah banyak digunakan di beberapa negara terutama di negara-negara maju dan telah diakui sebagai alat yang dapat menentukan dan meningkatkan kekuatan struktur perkerasan jalan. Prinsip kerja FWD adalah memberikan beban impuls terhadap struktur perkerasan, khususnya perkerasan lentur melalui pelat berbentuk sirkular (bundar) yang efeknya sama dengan kendaraan.

\section{METODE PENELITIAN}

\subsection{Identifikasi Masalah dan Tujuan Penelitian}

Dalam menentukan tebal dengan menggunakan Metode Bina Marga Revisi Juni 2017 dan AASHTO 1993 diperlukan berbagai pengujian dan survei yang dilaksanakan di lapangan, agar hasil dari perencanaan tebal perkerasan sesuai dengan kondisi di lapangan. Kedua metode ini digunakan untuk menganalisa tebal perkerasan yang nantinya akan dibandingkan supaya hasil tebal perkeresan dapat optimal dan efisien.

\subsection{Tinjauan Pustaka}

Sebelum penelitian dimulai terlebih dahulu akan dilakukan tinjauan pustaka. Tinjauan pustaka berisi tentang pemikiran atau teori-teori yang dapat dijadikan sebagai landasan atau studi literatur dalam menyusun konsep penelitian ini. Perhitungan perkerasan ini tergantung dari hasil pengujian dan survei di lapangan yang bersumber dari Kementerian Pekerjaan Umum dan Perumahan Rakyat Direktorat Jenderal Bina Marga tentang Manual Perkerasan Jalan Revisi Juni 2017 (Nomor 04/SE/Db/2017) dan Guide for The Design of Pavement Structures, Washington D.C AASHTO 1993.

\subsection{Perbandingan Analisa Tebal Perkerasan}

Analisa tebal perkerasan akan ditentukan setelah melakukan studi literatur dan studi pustaka mengenai persyaratan dan standar yang berlaku. Hasil dari perbandingan analisa ini akan menghasilkan tebal perkerasan dengan metode yang dilakukan.

\subsubsection{Analisis Metode Bina Marga Revisi Juni 2017}

Untuk menentukan tebal overlay pada Metode Bina Marga Revisi Juni 2017 terdapat tiga prosedur tebal overlay berdasarkan beban lalu lintas:

1. Lalu lintas lebih kecil atau sama dengan 100.000 ESA4

Desain tebal overlay cukup dengan pendekatan lendutan maksimum $\left(\mathrm{D}_{0}\right)$ yang diukur dengan alat Benkelmean Beam, hitung dan masukkan nilai karakteristik dan beban lalu lintasi desain (ESA4) pada Gambar 1 maka akan diperoleh nilai tebal overlay pada sumbu vertikal. Tetapi jika pengukuran lendutan menggunakan alat Falling Weight Deflectometer (FWD) gunakan faktor penyesuaian sesuai pada Tabel 1. 


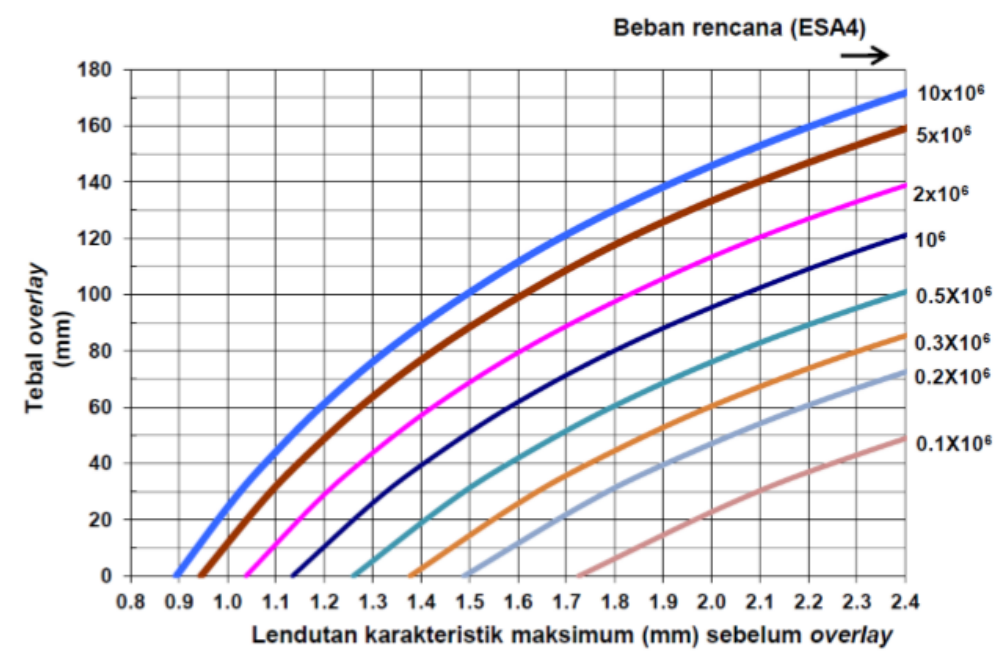

Gambar 1. Solusi overlay berdasarkan lendutan balik benkelmean beam untuk WMAPT $4^{\circ} \mathrm{C}$

(Sumber: Manual Desain Perkerasan Bina Marga Revisi Juni 2017)

Tabel 1. Faktor Penyesuain Lendutan $\left(D_{0}\right)$ FWD ke BB

\begin{tabular}{cccc}
\hline $\begin{array}{c}\text { Tebal Aspal Eksisting } \\
{[\mathbf{m m}]}\end{array}$ & Faktor & $\begin{array}{c}\text { Tebal Aspal Eksisting } \\
{[\mathbf{m m}]}\end{array}$ & Faktor \\
\hline 0 & 1,00 & 160 & 1,26 \\
\hline 20 & 1,12 & 180 & 1,28 \\
\hline 40 & 1,14 & 200 & 1,29 \\
\hline 60 & 1,16 & 220 & 1,31 \\
\hline 80 & 1,18 & 240 & 1,33 \\
\hline 100 & 1,20 & 260 & 1,34 \\
\hline 120 & 1,22 & 280 & 1,35 \\
\hline 140 & 1,24 & 300 & 1,36 \\
\hline
\end{tabular}

\section{(Sumber: Manual Desain Perkerasan Bina Marga Revisi Juni 2017)}

2. Lalu lintas lebih besar dari 100.000 ESA4

Pada jalan dengan lalu lintas lebih besar dari 100.000 ESA4 terdapat potensi retak telah lapisan aspal. Dengan demikian, kriteria deformasi permanen (pendekatan lendutan maksimum $D_{0}$ ) dan kriteria retak lelah (pendeketan lengkung lendutan, $D_{0}-D_{200}$ ) harus diperhitungkan. Gambar $\mathbf{3}$ menunjukkan skema dimensi fungsi lengkung lendutan (curvature function atau titik belok) dan Gambar 4 untuk mengetahui nilai tebal overlay.

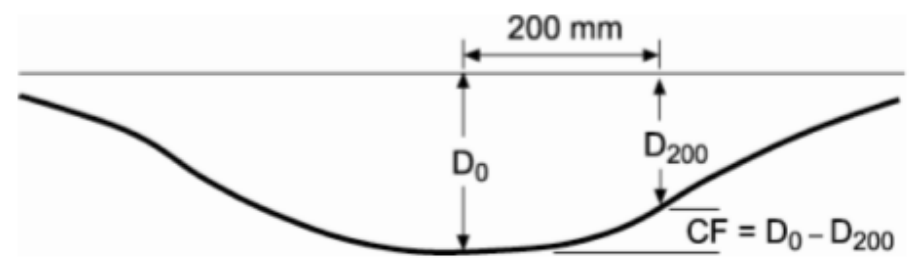

Gambar 3. Fungsi lengkung lendutan

(Sumber: Manual Desain Perkerasan Bina Marga Revisi Juni 2017) 
Perbandingan Analisa Perkerasan Metode Bina Marga Revisi Juni 2017 dan AASHTO 1993 (Studi Kasus pada Pekerjaan Rencana Preservasi Ruas Jalan Jatibarang-Langut TA 2017)

dengan:

$C F=$ titik belok lengkungan,

$D_{0}=$ lendutan maksimum [mm],

$D_{200}=$ lendutan yang terjadi pada titik yang berjarak $200 \mathrm{~mm}$ dari titik uji tersebut [mm].

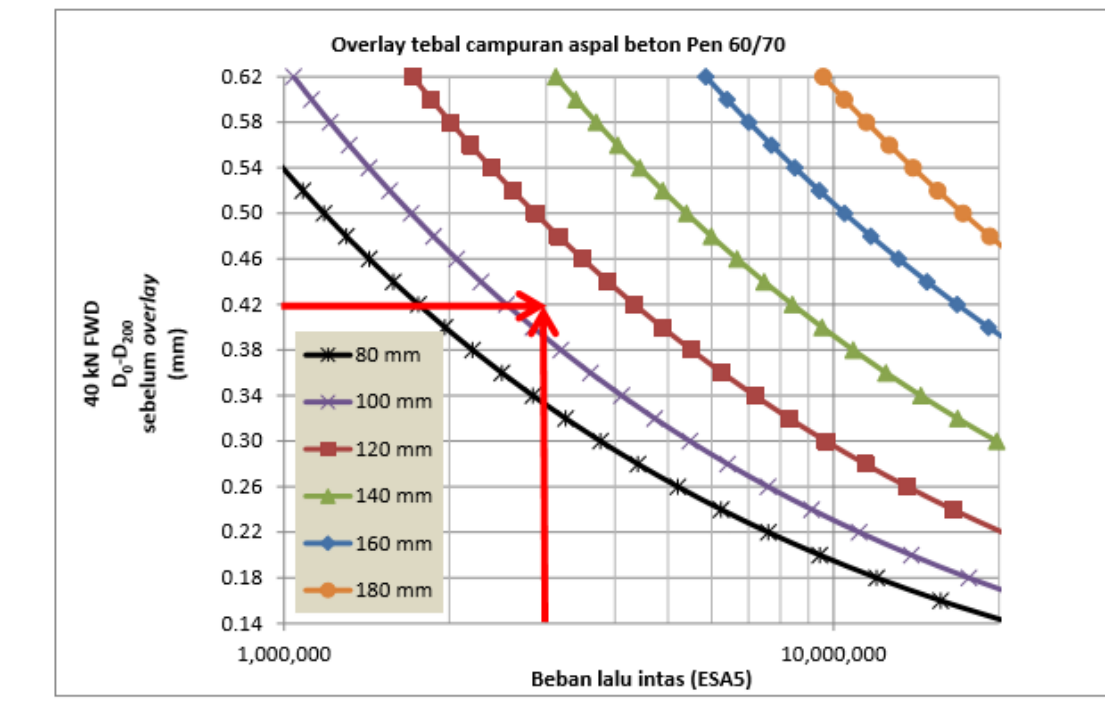

\section{Gambar 4. Tebal overlay aspal konvensional untuk mencegah retak akibat lelah pada MAPT $>35^{\circ} \mathrm{C}$ \\ (Sumber: Manual Desain Perkerasan Bina Marga Revisi Juni 2017)}

3. Lalu lintas lebih besar $10 * 10^{6}$ ESA4 atau $20 * 10^{6}$ ESA5

Untuk pekerjaaan rehabilitasi dengan beban lalu lintas lebih besar daripada $10 *$ $10^{6}$ ESA4 atau lebih besar daripada $20 * 10^{6}$ ESA5 harus digunakan prosedur mekanistik empiris atau metode-metode Pt T-01-2002-B atau metode AASHTO 1993. Pada prosedur pelapisan tambah perkerasan lentur berdasarkan lendutan permukaan Pt T-01-2002-B atau AASHTO 1993 tempereatur standar untuk lendutan maksimum $\left(D_{0}\right)$ yang digunakan adalah $68^{\circ} \mathrm{F}$ atau $20^{\circ} \mathrm{C}$. Dengan demikian, lendutan maksimum pada temperatur saat pengukuran harus distrandarkan ke temperatur $20^{\circ} \mathrm{C}$.

\subsubsection{Analisis Metode AASHTO 1993}

Menurut Fahmi, D. (2017) metode AASHTO 1993 menyediakan cara untuk melakukan desain tebal lapis tambahan pada struktur perkerasan lentur, salah satu caranya adalah cara Nondestrcutive Deflection Test (NDT). Cara ini menggunakan nilai modulus perkerasan yang diperkirakan dari proses back calculation terhadap cekung lendutan. Terdapat beberapa faktor yang mempengaruhi perencanaan tebal perkerasan lentur tebal lapis tambah dengan metode AASHTO 1993 yaitu:

1. Modulus tanah dasar, $M_{R}$ [psi] dapat dihitung menggunakan Persamaan 1

$$
M_{R}=\frac{0,24 \mathrm{P}}{\mathrm{d}_{r} r}
$$

dengan:

$P \quad=$ beban survei [pounds],

$d_{r}=$ lendutan pada jarak offset dari pusat beban [inch],

$r \quad=$ jarak offset [inch]. 
2. Modulus lapisan perkerasan, $E_{p}$ [psi] dapat dihitung menggunakan Persamaan 2

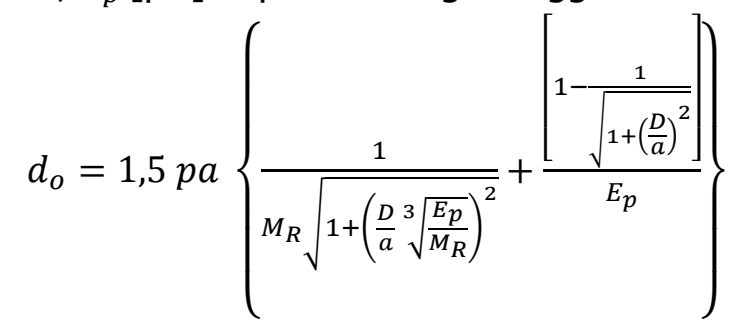

dengan:

$d_{0}=$ lendutan maksimum di titik pusat beban [inch],

$p=$ tekanan pada pelat beban [psi],

$a \quad=$ jari-jari pelat beban [inch].

3. Nilai $M_{R}$ dan nilai $E_{p}$ berlaku jika memenuhi persyaratan pada Persamaan 3

$$
a_{e}=\sqrt{\left[a^{2}+\left(D \sqrt[3]{\frac{E_{p}}{M_{R}}}\right)^{2}\right]}
$$

dengan:

$a_{e}=$ radius stress bulb pada pada permukaan subgrade perkerasan [inch],

$a=$ NDT radius beban [inch],

$D=$ total ketebalan lapisan perkerasan diatas tanah dasar [inch],

$E_{p}=$ modulus efektif semua lapisan perkerasan diatas tanah dasar [psi].

4. Grafik faktor koreksi temperatur untuk struktur perkerasan dengan lapisan fondasi agregat menurut AASHTO 1993 dapat dilihat pada Gambar 5.

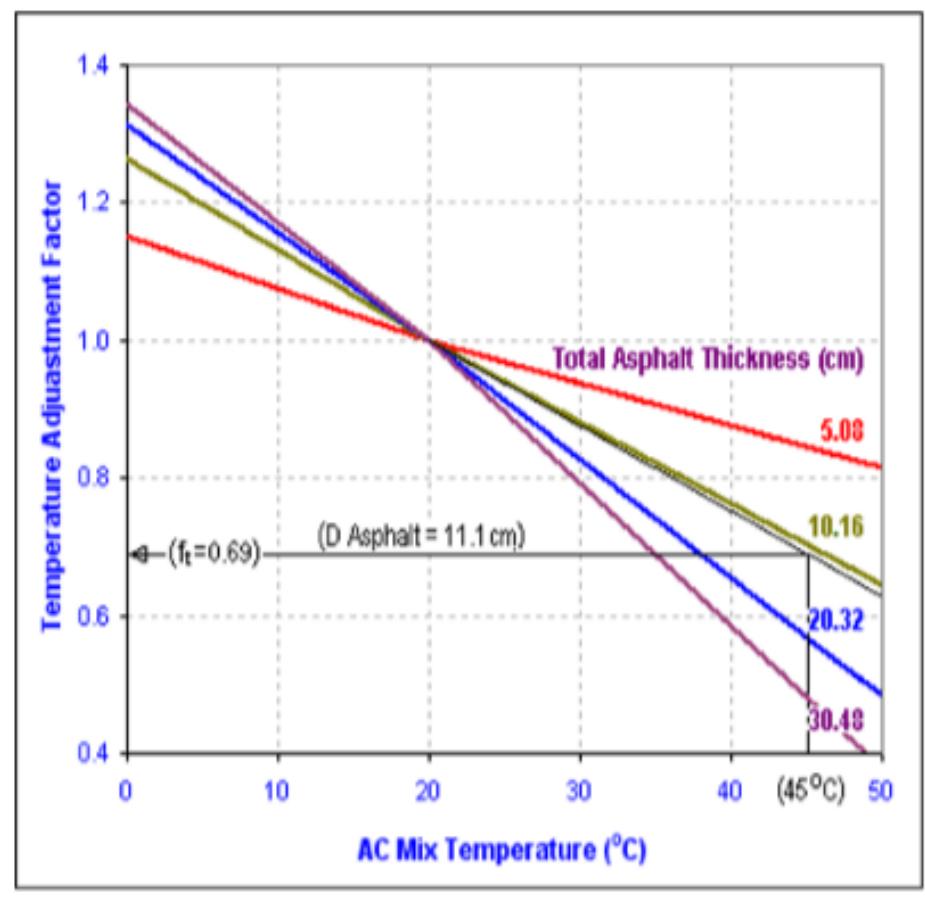

Gambar 5. Grafik faktor koreksi temperatur (Sumber: AASHTO, 1993)

5. Index tebal perkerasan efektif Structural Number Effective, Sneff [inch] dapat dihitung menggunakan Persamaan 4. 
Perbandingan Analisa Perkerasan Metode Bina Marga Revisi Juni 2017 dan AASHTO 1993 (Studi Kasus pada Pekerjaan Rencana Preservasi Ruas Jalan Jatibarang-Langut TA 2017)

$$
I T P_{e f f}=0,0045 D \sqrt[3]{E_{p}}
$$

dengan:

$I T P_{\text {eff }}=$ Indeks Tebal Perkerasan efektif,

$D=$ total ketebelan lapisan perkerasan diatas tanah dasar [inch],

$E_{p} \quad=$ modulus efektif semua lapisan perkerasan diatas tanah dasar [psi].

6. Indeks Tebal Perkerasan desain ITP/SN Structural Number [inch] dapat dihitung menggunakan Persamaan 5.

$$
\begin{aligned}
\log _{10} W_{18}= & Z_{R} * S_{o}+9,36 * \log _{10}(I T P+1)-0,20+\frac{\log _{10}\left[\frac{\Delta P S I}{4,2-1,5}\right]}{0,4+\frac{1094}{(I T P+1)^{5,19}}}+ \\
& 2,32 * \log _{10} * M_{R} \text { Desain }-8,07
\end{aligned}
$$

dengan:

$W_{18} \quad=$ perkiraan tebal pengulagan beban sumbu standar selama masa layan [ESA],

$Z_{R} \quad=$ konstanta normal pada tingkat probabilitas yang diinginkan,

$S_{0} \quad=$ kombinasi deviasi standar dari perkiraan beban lalu lintas dan kerusakan struktur perkerasan,

$\triangle P S I \quad=$ penurunan nilai kondisi struktural perkerasan yang diizinkan .

7. Menghitung tebal lapisan tambahan, $D_{o l}$ [inch] dapat dihitung menggunakan Persamaan

6.

$$
D_{o l}=\frac{\left(I T P-I T P_{e f f}\right)}{a_{o l}}
$$

dengan:

$a_{o l} \quad=$ koefisien tebal lapisan perkerasan efektif.

\subsection{Pengumpulan Data Primer Berdasarkan Survei dan Pengujian}

Untuk mendapatkan tebal perkerasan yang sesuain dengan metode yang digunakan diperlukan beberapa data pengujian dan survei yang dilakukan untuk menyelesaikan penelitian ini. Pengujian dan survei yang dilakukan yaitu pengujian lendutan dengan alat FWD, survei lalu lintas (traffic counting) dan survei kondisi jalan.

\subsection{Pengumpulan Data Sekunder Daya Dukung Tanah Dasar}

Diperlukan data daya dukung tanah dasar untuk mengetahui nilai CBR agar dalam perencanaan desain perkerasan bisa lebih optimal sesuai dengan kondisi perkerasan di lapangan yang akan diteliti.

\subsection{Pengolahan Data}

Pada tahap ini peneliti akan mengolah literatur-literatur yang telah dikumpulkan. Pengolahan data yang dilakukan adalah mendesain tebal perkerasan sesuai pengujian dan survei yang dilakukan dengan menggunakan metode Bina Marga Revisi Juni 2017 dan AASHTO 1993, lalu hasil dari tebal perkerasan akan dibandingkan.

\subsection{Simpulan dan Saran}

Dari hasil analisa ini akan dihasilkan tebal perkerasan dengan menggunakan metode Bina Marga Revisi Juni 2017 dan AASHTO 1993 yang nantinya akan menghasilkan tebal perkerasan sesuai dengan pengujian dan survei yang dilakukan di lapangan, lalu hasil tebal perkerasan dengan menggunakan kedua metode tersebut akan dibandingakan sesuai dengan kebutuhan 
di ruas jalan Jatibarang-Langut. Serta memberikan beberapa saran untuk penelitian selanjutnya.

\section{PENGOLAHAN DATA DAN ANALISIS}

Dari hasil perhitungan didapatkan rekapitulasi nilai CESA metode Bina Marga Revisi Juni 2017 dapat dilihat pada Tabel 2 dan nilai CESA metode AASHTO 1993 dapat dilihat pada Tabel 3. Grafik perbandingan nilai CESA metode Bina Marga Revisi Juni 2017 dan AASHTO 1993 dapat dilihat pada Gambar 6.

Tabel 2. Rekapitulasi Nilai CESA Bina Marga Revisi Juni 2017

\begin{tabular}{|c|c|c|c|c|c|c|c|c|}
\hline No & $\begin{array}{l}\text { Jenis } \\
\text { Kendaraan }\end{array}$ & $\begin{array}{l}\text { Nama } \\
\text { Kendaraan }\end{array}$ & $\begin{array}{l}\text { LHR } \\
2017\end{array}$ & $\begin{array}{l}\text { LHR } \\
2018\end{array}$ & $\begin{array}{l}\text { LHR } \\
2028\end{array}$ & $\begin{array}{c}\text { VDF4 } \\
\text { NORMAL }\end{array}$ & $\begin{array}{l}\text { ESA } \\
2018\end{array}$ & ESA 2028 \\
\hline 1 & $5 B$ & Bus Besar & 458 & 475 & 704 & 1 & 138.869 & 2.265 .680 \\
\hline 2 & $6 \mathrm{~A}$ & Truk 2 Sumbu & 1.824 & 1.896 & 2.807 & 0,55 & 304.532 & 4.968 .536 \\
\hline 3 & $6 \mathrm{~B}$ & $\begin{array}{c}\text { Truk } 3 \text { Sumbu - } \\
\text { Ringan }\end{array}$ & 1.501 & 1.561 & 2.310 & 4 & 1.822 .948 & 29.741 .923 \\
\hline 4 & $7 \mathrm{~A}$ & $\begin{array}{c}\text { Truk } 3 \text { Sumbu - } \\
\text { Sedang }\end{array}$ & 1.470 & 1.529 & 2.263 & 4,3 & 1.919 .188 & 31.312 .115 \\
\hline 5 & $7 \mathrm{~B}$ & $\begin{array}{c}\text { Truk } 4 \text { Sumbu - } \\
\text { Trailer }\end{array}$ & 951 & 989 & 1.464 & 9,4 & 2.714.309 & 44.284 .746 \\
\hline \multirow[t]{2}{*}{6} & 7C & $\begin{array}{c}\text { Truk } 5 \text { Sumbu - } \\
\text { Trailer }\end{array}$ & 1.062 & 1.104 & 1.634 & 7,4 & 2.384 .634 & 38.906 .002 \\
\hline & & & & & & CESA & 9.284 .480 & 151.479 .002 \\
\hline
\end{tabular}

\section{Catatan:}

LHR = Lalu Lintas Harian Rata-rata.

Tabel 3. Rekapitulasi Nilai CESA AASHTO 1993

\begin{tabular}{|c|c|c|c|c|c|c|c|}
\hline No & $\begin{array}{c}\text { Nama } \\
\text { Kendaraan }\end{array}$ & LHR 2017 & $\begin{array}{l}\text { VDF MST } \\
8 \text { ton }\end{array}$ & DA & DL & $\mathbf{N}$ & ESA 2028 \\
\hline 1 & Sedan, Jep & 3.028 & 0,0024 & 1 & 0,8 & 12,01 & 24.793 \\
\hline 2 & Angkot, Combi & 1.039 & 0,3199 & 1 & 0,8 & 12,01 & 1.165 .882 \\
\hline 3 & Pickup & 2.181 & 0,3199 & 1 & 0,8 & 12,01 & 2.446 .670 \\
\hline 4 & Bus Kecil & 226 & 0,0459 & 1 & 0,8 & 12,01 & 36.433 \\
\hline 5 & Bus Besar & 457 & 0,3011 & 1 & 0,8 & 12,01 & 482.812 \\
\hline 6 & $\begin{array}{l}\text { Truk } 2 \text { Sumbu } \\
\text { (4 Roda) }\end{array}$ & 1.823 & 1,0110 & 1 & 0,8 & 12,01 & 6.464 .418 \\
\hline 7 & $\begin{array}{l}\text { Truk } 2 \text { Sumbu } \\
\text { (6 Roda) }\end{array}$ & 1.501 & 1,2249 & 1 & 0,8 & 12,01 & 6.446 .580 \\
\hline 8 & $\begin{array}{l}\text { Truk Besar } \\
3 \text { Sumbu } \\
\text { (10 Roda) }\end{array}$ & 1.470 & 2,61 & 1 & 0,8 & 12,01 & 13.452 .137 \\
\hline 9 & $\begin{array}{c}\text { Truk } \\
\text { Gandengan }\end{array}$ & 951 & 3,5066 & 1 & 0,8 & 12,01 & 11.692 .925 \\
\hline \multirow[t]{2}{*}{10} & $\begin{array}{c}\text { Truk Trailer } \\
4 \text { Sumbu : } \\
1.2-22\end{array}$ & 1.061 & 3,0711 & 1 & 0,8 & 12,01 & 11.428 .465 \\
\hline & & & & & & CESA & 53.641 .295 \\
\hline
\end{tabular}


Perbandingan Analisa Perkerasan Metode Bina Marga Revisi Juni 2017 dan AASHTO 1993 (Studi Kasus pada Pekerjaan Rencana Preservasi Ruas Jalan Jatibarang-Langut TA 2017)

Catatan:

DA = Distribusi Arah,

$\mathrm{DL} \quad=$ Distribusi Lajur,

$\mathrm{N} \quad=$ Faktor Umur Rencana.

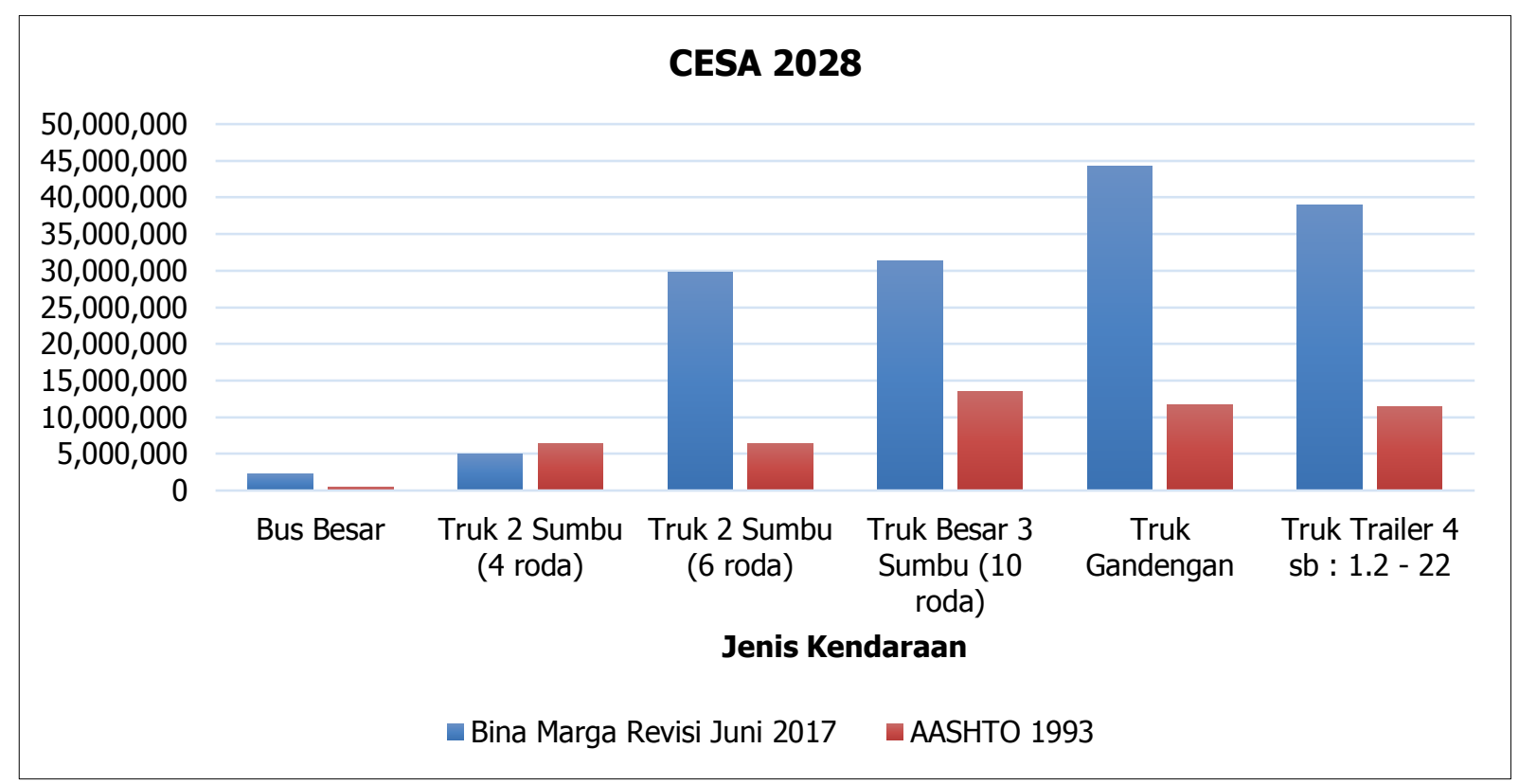

\section{Gambar 6. Grafik perbandingan nilai CESA Bina Marga Revisi Juni 2017 dan AASHTO 1993}

Berdasarkan tabel di atas didapat nilai CESA metode Bina Marga Revisi Juni 2017 151.479.002 yang artinya nilai lalu lintas lebih besar $10 * 10^{6}$ ESA4 atau $20 * 10^{6} E S A 5$ maka perhitungan tebal perkerasan harus menggunakan prosedur mekanistik empiris atau metode AASHTO 1993. Tabel 4 menunjukkan hasil rekapitulasi perhitungan nilai modulus tanah dasar dan modulus perkerasan. Tabel 5 menunjukkan hasil rekapitulasi perhitungan tebal perkerasan dengan menggunakan CESA metode Bina Marga Revisi Juni 2017 dan menunjukkan hasil rekapitulasi perhitungan tebal perkerasan dengan menggunakan CESA metode AASHTO 1993, serta Gambar 7 grafik perbandingan tebal perkerasan kedua metode tersebut.

Tabel 4. Rekapitulasi Perhitungan Nilai Modulus Tanah Dasar dan Modulus Perkerasan

\begin{tabular}{cccccccc} 
No & $\begin{array}{c}\text { Lokasi } \\
(\mathbf{K M})\end{array}$ & $\begin{array}{c}\text { Modulus } \\
\text { Tanah } \\
\text { Dasar } \\
(\mathbf{M P a})\end{array}$ & $\begin{array}{c}\text { Modulus } \\
\text { Perkerasan } \\
(\mathbf{M P a})\end{array}$ & No & Lokasi (KM) & $\begin{array}{c}\text { Modulus } \\
\text { Tanah Dasar } \\
(\mathbf{M P a})\end{array}$ & $\begin{array}{c}\text { Modulus } \\
\text { Perkerasan } \\
(\mathbf{M P a})\end{array}$ \\
\hline 1 & $49+900$ & 74 & $7.332,30$ & 9 & $50+700$ & 27,46 & 769,52 \\
\hline 2 & $50+000$ & 56,45 & $10.232,23$ & 10 & $50+800$ & 45,15 & $1.289,73$ \\
\hline 3 & $50+100$ & 37,10 & $2.019,47$ & 11 & $50+900$ & 30,10 & $1.410,39$ \\
\hline 4 & $50+200$ & 43,59 & $1.779,74$ & 12 & $51+000$ & 36,40 & $1.702,52$ \\
\hline 5 & $50+300$ & 38,61 & $1.594,90$ & 13 & $51+100$ & 28,06 & 855,98 \\
\hline 6 & $50+400$ & 49 & $2.759,76$ & 14 & $51+200$ & 36,38 & $1.553,18$ \\
\hline 7 & $50+500$ & 29,79 & 666,03 & 15 & $51+300$ & 23,88 & $1.050,28$ \\
\hline 8 & $50+600$ & 36,13 & $1.480,44$ & 16 & $51+400$ & 34,27 & $1.325,24$ \\
\hline
\end{tabular}


Tabel 4. Rekapitulasi Perhitungan Nilai Modulus Tanah Dasar dan Modulus Perkerasan (lanjutan)

\begin{tabular}{cccccccc} 
No & $\begin{array}{c}\text { Lokasi } \\
(\mathbf{K M})\end{array}$ & $\begin{array}{c}\text { Modulus } \\
\text { Tanah } \\
\text { Dasar } \\
(\mathbf{M P a})\end{array}$ & $\begin{array}{c}\text { Modulus } \\
\text { Perkerasan } \\
(\mathbf{M P a})\end{array}$ & No & Lokasi (KM) & $\begin{array}{c}\text { Modulus } \\
\text { Tanah Dasar } \\
\text { (MPa) }\end{array}$ & $\begin{array}{c}\text { Modulus } \\
\text { Perkerasan } \\
(\mathbf{M P a})\end{array}$ \\
\hline 17 & $51+500$ & 32,63 & $1.400,26$ & 25 & $52+300$ & 30,85 & 655,76 \\
\hline 18 & $51+600$ & 26,08 & 818,68 & 26 & $52+400$ & 44,19 & $1.220,10$ \\
\hline 19 & $51+700$ & 28,74 & 959,68 & 27 & $52+500$ & 36,62 & $1.770,78$ \\
\hline 20 & $51+800$ & 20,40 & 746,70 & 28 & $52+600$ & 28,97 & 806,20 \\
\hline 21 & $51+900$ & 27,24 & 942,03 & 29 & $52+700$ & 23,56 & 643,90 \\
\hline 22 & $52+000$ & 30,06 & 997,33 & 30 & $52+800$ & 22,88 & 578,61 \\
\hline 23 & $52+100$ & 34,74 & $1.395,50$ & 31 & $52+900$ & 29,19 & 811,31 \\
\hline 24 & $52+200$ & 32,97 & $5.600,68$ & 32 & $53+000$ & 23,33 & 648,31 \\
\hline & & & & Maksimum & 74,00 & $10.232,23$ \\
\hline & & & & Minimum & 20,40 & 578,61 \\
\hline & & & & Standar Deviasi & 10,86 & $2.079,27$ \\
\hline
\end{tabular}

Tabel 5. Rekapitulasi Perhitungan Tebal Perkerasan

\begin{tabular}{|c|c|c|c|c|c|}
\hline No & Lokasi (KM) & $\begin{array}{l}\text { CESA Bina Marga } \\
\text { Revisi Juni } 2017\end{array}$ & $\begin{array}{c}\text { Tebal Perkrasan, } \\
D_{o l}[\mathrm{~cm}]\end{array}$ & $\begin{array}{c}\text { CESA } \\
\text { AASHTO } 1993\end{array}$ & $\begin{array}{c}\text { Tebal } \\
\text { Perkerasan, } \\
D_{o l}[\mathrm{~cm}]\end{array}$ \\
\hline 1 & $49+900$ & 151.479 .002 & 0 & 53.641 .295 & 0 \\
\hline 2 & $50+000$ & 151.479 .002 & 0 & 53.641 .295 & 0 \\
\hline 3 & $50+100$ & 151.479 .002 & 22,12 & 53.641 .295 & 15,84 \\
\hline 4 & $50+200$ & 151.479 .002 & 21,00 & 53.641 .295 & 14,97 \\
\hline 5 & $50+300$ & 151.479 .002 & 23,81 & 53.641 .295 & 17,59 \\
\hline 6 & $50+400$ & 151.479 .002 & 14,91 & 53.641 .295 & 9,00 \\
\hline 7 & $50+500$ & 151.479 .002 & 34,66 & 53.641 .295 & 28,06 \\
\hline 8 & $50+600$ & 151.479 .002 & 25,44 & 53.641 .295 & 19,15 \\
\hline 9 & $50+700$ & 151.479 .002 & 34,91 & 53.641 .295 & 28,24 \\
\hline 10 & $50+800$ & 151.479 .002 & 23,41 & 53.641 .295 & 17,44 \\
\hline 11 & $50+900$ & 151.479 .002 & 28,60 & 53.641 .295 & 22,06 \\
\hline 12 & $51+000$ & 151.479 .002 & 24,03 & 53.641 .295 & 17,74 \\
\hline 13 & $51+100$ & 151.479 .002 & 33,81 & 53.641 .295 & 27,14 \\
\hline 14 & $51+200$ & 151.479 .002 & 24,88 & 53.641 .295 & 18,59 \\
\hline 15 & $51+300$ & 151.479 .002 & 34,77 & 53.641 .295 & 27,85 \\
\hline 16 & $51+400$ & 151.479 .002 & 27,18 & 53.641 .295 & 20,83 \\
\hline 17 & $51+500$ & 151.479 .002 & 27,46 & 53.641 .295 & 21,05 \\
\hline 18 & $51+600$ & 151.479 .002 & 35,29 & 53.641 .295 & 28,49 \\
\hline 19 & $51+700$ & 151.479 .002 & 32,56 & 53.641 .295 & 25,89 \\
\hline
\end{tabular}


Perbandingan Analisa Perkerasan Metode Bina Marga Revisi Juni 2017 dan AASHTO 1993 (Studi Kasus pada Pekerjaan Rencana Preservasi Ruas Jalan Jatibarang-Langut TA 2017)

Tabel 5. Rekapitulasi Perhitungan Tebal Perkerasan (lanjutan)

\begin{tabular}{ccccrc}
\hline No & Lokasi (KM) & $\begin{array}{c}\text { CESA Bina Marga } \\
\text { Revisi Juni 2017 }\end{array}$ & $\begin{array}{c}\text { Tebal Perkrasan, } \\
\boldsymbol{D}_{\text {ol }}[\mathbf{C m}]\end{array}$ & $\begin{array}{c}\text { CESA } \\
\text { AASHTO 1993 }\end{array}$ & $\begin{array}{c}\text { Tebal } \\
\text { Perkerasan, } \\
\boldsymbol{D}_{\text {ol }}[\mathbf{c m}]\end{array}$ \\
\hline 20 & $51+800$ & 151.479 .002 & 39,95 & 53.641 .295 & 32,78 \\
\hline 21 & $51+900$ & 151.479 .002 & 33,53 & 53.641 .295 & 26,80 \\
\hline 22 & $52+000$ & 151.479 .002 & 31,56 & 53.641 .295 & 24,96 \\
\hline 23 & $52+100$ & 151.479 .002 & 26,54 & 53.641 .295 & 20,19 \\
\hline 24 & $52+200$ & 151.479 .002 & 11,80 & 53.641 .295 & 5,32 \\
\hline 25 & $52+300$ & 151.479 .002 & 34,26 & 53.641 .295 & 27,72 \\
\hline 26 & $52+400$ & 151.479 .002 & 24,20 & 53.641 .295 & 18,17 \\
\hline 27 & $52+500$ & 151.479 .002 & 23,59 & 53.641 .295 & 17,31 \\
\hline 28 & $52+600$ & 151.479 .002 & 33,75 & 53.641 .295 & 27,14 \\
\hline 29 & $52+700$ & 151.479 .002 & 38,64 & 53.641 .295 & 31,65 \\
\hline 30 & $52+800$ & 151.479 .002 & 39,80 & 53.641 .295 & 32,81 \\
\hline 31 & $52+900$ & 151.479 .002 & 33,57 & 53.641 .295 & 26,97 \\
\hline 32 & $53+000$ & 151.479 .002 & 38,72 & 53.641 .295 & 31,80 \\
\hline & Maksimum & 39,95 & Maksimum & 32,81 \\
\hline & Minimum & 0,00 & Minimum & 0,00 \\
\hline & Rata-Rata & 27,46 & Rata-Rata & 21,36 \\
\hline & & 9,98 & Standar Deviasi & 8,69 \\
\hline & & & &
\end{tabular}

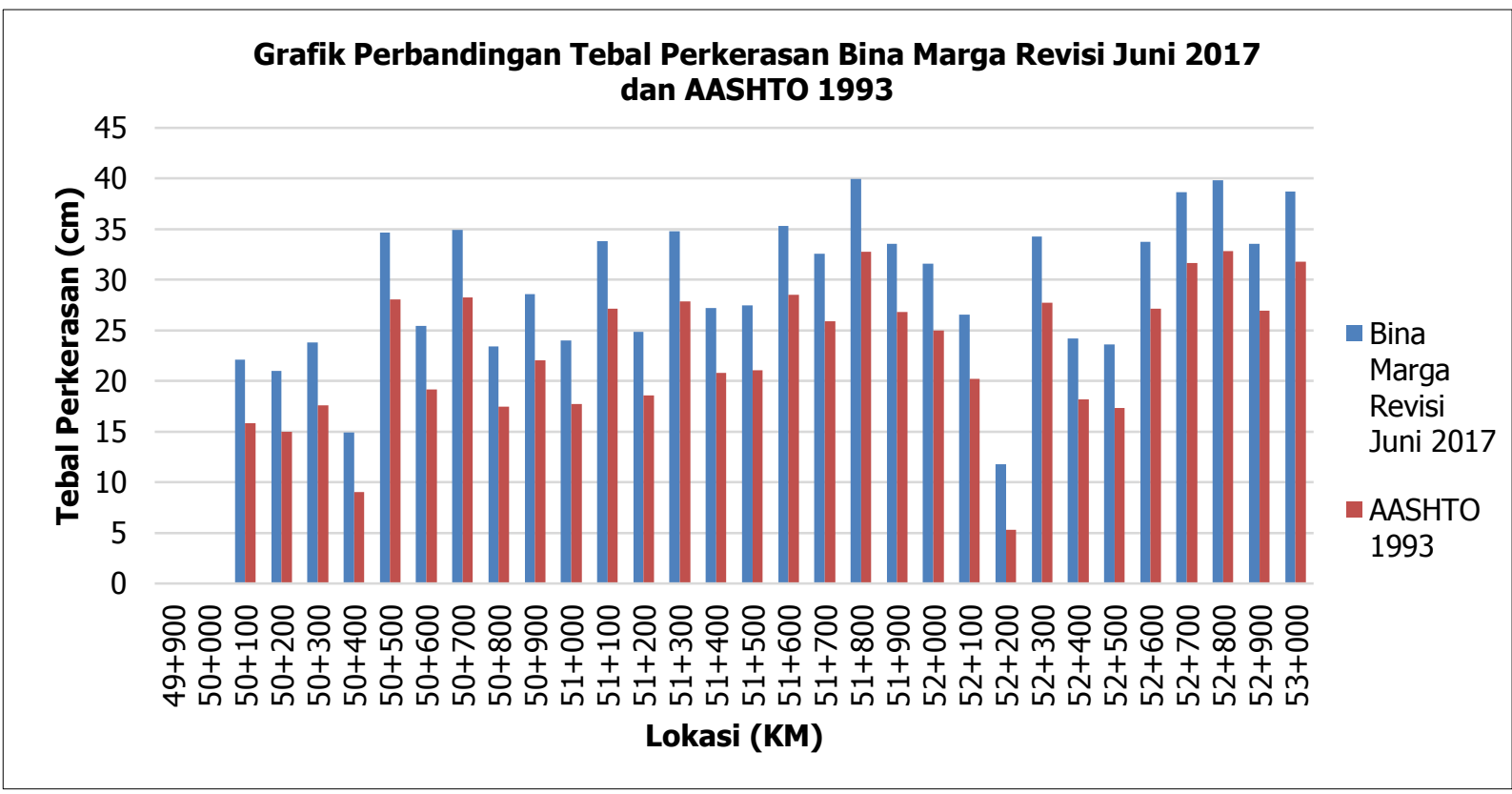

\section{Gambar 7. Grafik perbandingan tebal perkerasan}

Berdasarkan perhitungan pada setiap titik pengujian FWD pada Tabel 5, maka untuk menentukan besarnya tebal lapis tambah yang diperlukan untuk mewakili ruas jalan Jatibarang-Langut KM 49+900-53+000 arah Jakarta dengan tingkat kepercayaan 98\% untuk jalan arteri diperoleh: 
- $\quad H$ wakil untuk perhitungan CESA dengan metode Bina Marga Revisi Juni 2017 sebesar 151.479.002 dengan asumsi tebal perkerasan eksisting $400 \mathrm{~mm}$ yaitu:

Hwakil $=d R+2 s=27,46+2 * 9,98=47,42 \mathrm{~cm}$

- $\quad$ Hwakil untuk perhitungan CESA dengan metode AASHTO 1993 sebesar 53.641.295 dengan asumsi tebal perkerasan eksisting $400 \mathrm{~mm}$ yaitu:

Hwakil $=d R+2 s=21,36+2 * 8,69=38,74 \mathrm{~cm}$

\section{KESIMPULAN}

Berdasarkan hasil penelitian dan pembahasan dapat disimpulkan sebagai berikut:

1. Berdasarkan hasil analisis perhitungan untuk didapatkan nilai CESA pada setiap metode yaitu Bina Marga Revisi Juni 2017 dan AASHTO 1993 diperoleh hasil yang berbeda cukup signifikan yaitu metode Bina Marga Revisi Juni 2017 sebesar 151.479.002 dan AASHTO 1993 sebesar 53.641.295.

2. Faktor yang mempengaruhi nilai CESA Bina Marga Revisi Juni 2017 lebih besar dari AASHTO 1993 adalah nilai VDF, dimana nilai VDF metode Bina Marga Revisi Juni 2017 disesuaikan dengan kondisi kendaraan yang berada di Indonesia dengan melakukan Survei WIM (Weigh In Motion/pengukuran berat sumbu kendaraan secara dinamis).

3. Dalam perhitungan CESA metode Bina Marga Revisi Juni 2017 didapat sebesar 151.479.002, karena dalam peraturan metode Bina Marga Revisi Juni 2017 apabila nilai CESA lebih besar dari $10 * 10^{6}$ ESA4 atau $20 * 10^{6}$ ESA5 perhitungan tebal perkerasan harus menggunakan prosedur mekanistik empiris atau dengan metode AASHTO 1993.

4. Dari hasil perhitungan menggunakan metode AASHTO 1993 melalui pengujian dengan menggunakan alat FWD didapat hasil nilai modulus tanah dasar rata-rata sebesar 34,34 $\mathrm{MPa}$ dan nilai modulus perkerasan rata-rata sebesar 1.806,80 $\mathrm{MPa}$.

5. Hasil analisis perhitungan tebal lapis tambah ruas Jalan Jatibarang-Langut KM 49+90053+000 arah Jakarta dengan tingkat kepercayaan $98 \%$ pada jalan arteri melalui pengujian lendutan dengan menggunakan alat FWD metode AASHTO 1993 dengan nilai CESA yang berbeda didapat metode Bina Marga Revisi Juni 2017 dengan nilai CESA 151.479.002 diperoleh 47,42 cm dan AASHTO 1993 dengan nilai CESA 53.641 .295 diperoleh $38,74 \mathrm{~cm}$.

\section{DAFTAR RUJUKAN}

AASHTO. (1993). Guide for The Design of Pavement Structures. Washington DC.

Fahmi, D. (2017). Perhitungan Tebal Lapis Tambah Berdasar Data FWD. Sosialisasi Perhitungan Tebal Perkerasan Melalui Data FWD (hal. 3-28). Bandung: Pusat Litbang dan Jembatan, Badan Penelitian dan Pengembangan, Kementerian Pekerjaan Umum dan Perumahan Rakyat.

Menteri Pekerjaan Umum. (2004). Pedoman Pencacahan Lalu Lintas dengan Cara Manual. Jakarta: Direktorat Jenderal Bina Marga, Departemen Permukiman dan Prasarana Wilayah.

Menteri Pekerjaan Umum. (2017). Manual Perkerasan Jalan (Revisi Juni 2017) Nomor 04/SE/Db/2017. Jakarta: Direktorat Jenderal Bina Marga.

Sukirman, S. (2010). Perencanaan Tebal Struktur Perkerasan Lentur. Bandung: NOVA. 